\section{Highly Chemoselective Formation of Aldehyde Enamines under Very Mild Reaction Conditions}

Guillaume Bélanger,* Michaël Doré, Frédéric Ménard, and Véronique Darsigny

Laboratoire de Synthèse Organique et de Développement de Stratégies de Synthèse, Département de Chimie, Université de Sherbrooke, 2500 boulevard Université, Sherbrooke, Québec, $J 1 K 2 R 1$, Canada

guillaume.belanger@USherbrooke.ca

Received May 30, 2006

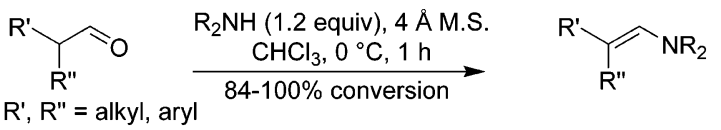

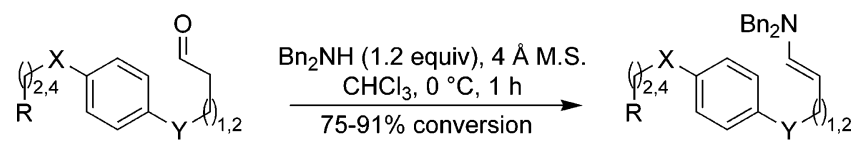

$\mathrm{X}$ or $\mathrm{Y}=\mathrm{O} ; \mathrm{R}=$ alkene, ester, acid, acetal, ketone, silylether

Although ketone enamines are widely used in organic synthesis, aldehyde enamines are rarely employed due to the limitations of their preparation using known methods (need for acid or base, excess of amine, and/or elevated temperature). We have successfully developed rapid and particularly mild condensation conditions $\left(1 \mathrm{~h}, 0{ }^{\circ} \mathrm{C}, 1.2\right.$ equiv of amine) leading to di- and trisubstituted enamines with excellent conversion (84-100\%). Remarkably high chemoselectivity was observed with complete discrimination between aldehyde and ketone, among other functional groups positively tested.

Enamines are of great utility in organic synthesis. They are employed as nucleophiles in various addition reactions, ${ }^{1}$ and we recently used them in intramolecular Vilsmeier-Haack addition to activated amides. ${ }^{2}$ Although the preparation and use of ketone enamines are well documented in the literature, ${ }^{3}$ enamines derived from aldehydes bring up a much greater challenge. ${ }^{4}$ The usual conditions to prepare aldehyde enamines involve either strong Lewis acids $\left(\mathrm{TiCl}_{4}, \mathrm{AlCl}_{3}, \mathrm{SnCl}_{4} \text {, etc. }\right)^{5}$ or Brønsted acids (AcOH, PTSA) in refluxing solvent (benzene, toluene, or xylene). ${ }^{6}$ The preparation of aldehyde enamines was also effected in basic conditions $\left(\mathrm{K}_{2} \mathrm{CO}_{3}\right)$, either in refluxing xylene $^{7}$ or with a large excess of secondary amine at room

(1) For a review on electrophilic and nucleophilic substitution and addition reactions of enamines, see: Hickmott, P. W. In The Chemistry of Enamines, Part 1; Rappoport, Z., Ed.; John Wiley \& Sons: New York, 1994; Chapter 14, p 727.

(2) (a) Bélanger, G.; Larouche-Gauthier, R.; Ménard, F.; Nantel, M.; Barabé, F. Org. Lett. 2005, 7, 4431. (b) Bélanger, G.; Larouche-Gauthier, R.; Ménard, F.; Nantel, M.; Barabé, F. J. Org. Chem. 2006, 71, 704.

(3) (a) Hamadouche, M.; El Abed, D. J. Soc. Chim. Tun. 1999, 4, 337. (b) Eervinka, O. In The Chemistry of Enamines, Part 1; Rappoport, Z., Ed.; John Wiley \& Sons: New York, 1994; Chapter 9, p 467.

(4) Enamines derived from simple aldehydes are often unstable, being easily hydrolyzed, oxidized, or polymerized; see ref $3 \mathrm{~b}$.

(5) White, W. A.; Weingarten, H. J. Org. Chem. 1967, 32, 213. temperature over an extended amount of time (ca. 4 days). ${ }^{8,9}$ Moreover, the large majority of the reported aldehyde enamines were only purified by distillation, which limits greatly the application of these preparation methods to small and volatile molecules. The limitations of these methods, coupled to the isolation restrictions, probably explain why aldehyde enamines have never met the level of utilization of ketone enamines. ${ }^{10}$

We report herein the development of a very mild, rapid, and highly chemoselective formation of enamines derived from aldehydes, with a close to stoichiometric amount of secondary amine. We tested a series of secondary amines (dibenzylamine, diethylamine, morpholine, or pyrrolidine) in the condensation reaction with various aldehydes. Conversions to the enamines range from 87 to $100 \%$ with only 1.2 equiv of amine in the presence of molecular sieves after $1 \mathrm{~h}$ at $0{ }^{\circ} \mathrm{C}$ (Table 1 , entries 1-9). These very mild reaction conditions contrast markedly with reported procedures that require heat or excess of amine for an extended period of time. In fact, we even observed a drop in conversion yields and less clean ${ }^{1} \mathrm{H}$ NMR spectra of reaction aliquots when the condensations were run at elevated temperature $\left(80{ }^{\circ} \mathrm{C}\right)$ or for an extended period of time. ${ }^{11}$ The need for molecular sieves was verified: a conversion of $49 \%$ was obtained after $1 \mathrm{~h}$ in the absence of molecular sieves compared to $92 \%$ with the dehydrating agent (entry 1 , see footnote). Chloroform turned out to be the solvent of choice: the condensation of dibenzylamine and hydrocinnamaldehyde went up to $92 \%$ conversion in chloroform (entry 1), whereas 82 and $84 \%$ conversions were obtained when dichloromethane and 1,2-dichloroethane were used, respectively, with the latter showing a less clean reaction profile. ${ }^{12}$ With the more hindered diphenylacetaldehyde, although the condensation with 1.2 equiv of pyrrolidine was quantitative after $1 \mathrm{~h}$ (entry 9), 4 equiv of the bulkier dibenzylamine was necessary to get $84 \%$ conversion after $4 \mathrm{~h}$ (entry 10). However, when nonconjugated enamines were generated, even from hindered aldehydes, such as cyclohexanecarbaldehyde, the reaction still proceeded rapidly and quantitatively (entry 4). Not surprisingly, when the less nucleophilic $N$-methylaniline was used, the conversion to the corresponding enamine 11 was much slower $(35 \%$ after $1 \mathrm{~h})$ but could be raised to $88 \%$ upon treatment with 3 equiv of amine for $2 \mathrm{~h}$ (entry 11). We were only able to isolate and purify

(6) Stork, G.; Brizzolara, A.; Landesman, H.; Szmuszkovicz, J.; Terrell, R. J. Am. Chem. Soc. 1963, 85, 207.

(7) Allinger, N. L.; Graham, J. C.; Dewhurst, B. B. J. Org. Chem. 1974, $39,2615$.

(8) Brannock, K. C.; Bell, A.; Burpitt, R. D.; Kelly, C. A. J. Org. Chem. 1964, 29, 801.

(9) To the best of our knowledge, only one paper reports reaction conditions using molecular sieves and a secondary amine (piperidine, 1.1 equiv) in ether at low temperature for the preparation of a fairly hindered enamine as a single example. See: White, J. D.; Ruppert, J. F.; Avery, M. A.; Torii, S.; Nokami, J. J. Am. Chem. Soc. 1981, 103, 1813.

(10) Although aldehyde hydrazones can be used for alkylation reactions, strongly basic conditions are required to generate the corresponding nucleophile (Davenport, K. G.; Eichenauer, H.; Enders, D.; Newcomb, M.; Bergbreiter, D. E. J. Am. Chem. Soc. 1979, 101, 5654), which is not always appropriate (e.g., in Vilsmeier-Haack cyclization, ref 2).

(11) At $80{ }^{\circ} \mathrm{C}$ without molecular sieves, the conversion was fast, but the reaction was less clean than at $0{ }^{\circ} \mathrm{C}$, and the generated enamines decomposed extensively over time.

(12) We are confident that the reaction is not catalyzed by traces of acid in the chloroform or leaching from the molecular sieves since no conversion to the desired enamine was observed when $p$-toluenesulfonic acid or $\mathrm{BF}_{3}$. $\mathrm{OEt}_{2}$ was added to the reaction mixture. 
TABLE 1. Aldehyde Enamine Formation from Various Secondary Amines and Aldehydes

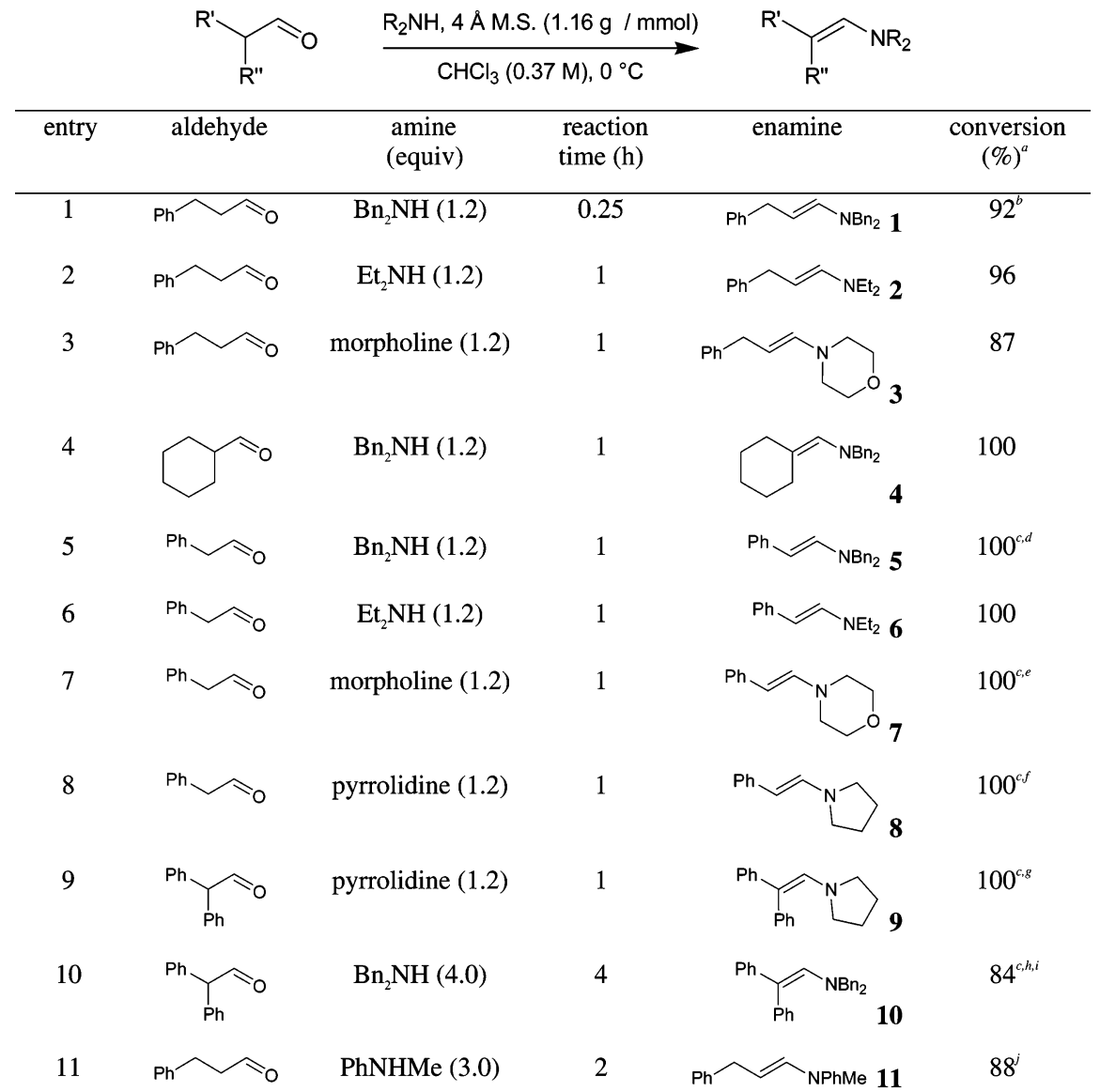

\footnotetext{
${ }^{a}$ Conversions determined by comparison of the integration of characteristic enamine versus aldehyde signals on ${ }^{1} \mathrm{H}$ NMR spectra of reaction aliquots and correlated to signals of pure enamines 5, 7, and 8. ${ }^{b}$ Conversion (49\%) obtained without $4 \AA$ molecular sieves. ${ }^{c}$ The product was unstable on silica gel and slowly decomposed during the purification. ${ }^{d}$ Isolated yield $(80 \%)$ after chromatographic purification. ${ }^{e}$ Isolated yield (63\%) after chromatographic purification. ${ }^{f}$ Isolated yield (41\%) after chromatographic purification. ${ }^{g}$ Isolated yield (64\%) after chromatographic purification. ${ }^{h}$ Conversion $(49 \%)$ obtained with only 1.2 equiv of $\mathrm{Bn}_{2} \mathrm{NH}$ after $1 \mathrm{~h} .{ }^{i}$ Isolated yield (71\%) after chromatographic purification. ${ }^{j}$ Conversion (35\%) obtained with only 1.2 equiv of PhNHMe after
} $1 \mathrm{~h}$.

aldehyde enamines stabilized by conjugation with one (entries 5-8) or two (entries 9 and 10) aromatic rings. However, the isolation yields were good to moderate $(41-80 \%)$, due to a slow decomposition of the aldehyde enamines on silica gel.

The greatest advantage of the reaction conditions we developed is the very high chemoselectivity for aldehyde enamine preparation in the presence of other functional groups on the same molecule. To show this, we synthesized a series of aromatic substrates with two functionalized branches in para positions. The first branch bore the aldehyde precursor to the enamine, and the second branch contained a functional group that was varied. The para orientation served to prevent potential intramolecular interference of the two functional groups during the preparation of the substrates and their subsequent condensation with dibenzylamine.

Schemes 1-4 describe the syntheses of the substrates, all derived from the known phenol 12. ${ }^{13}$ In Scheme 1, the phenol 12 was etherified with a silylated alcohol branch 13. ${ }^{14}$ The remaining ester moiety was then transformed to the aldehyde to provide the silyl ether aldehyde 16. The latter was treated in methanolic $\mathrm{HCl}$ to give the corresponding hydroxyacetal. The alcohol group was then oxidized to the acetal aldehyde $\mathbf{1 7}$ or transformed to the corresponding terminal alkene to give the alkene aldehyde $\mathbf{1 8}$ after hydrolysis of the acetal.
An aldehydic compound bearing a carboxylic acid group was also prepared. The ester and silyl ether of compound $\mathbf{1 4}$ were both hydrolyzed to the hydroxyacid $\mathbf{1 9}$ (Scheme 2). The alcohol was then oxidized to the aldehyde 20 with IBX. ${ }^{15}$

In Scheme 3, the alcohol $\mathbf{1 5}$ was protected with a THP, and the silyl ether was transformed to the corresponding ester 22. The THP was then removed, and the alcohol was oxidized to the aldehyde $\mathbf{2 3}$.

Finally, addition of methyl Grignard to aldehyde $\mathbf{2 1}$ afforded the secondary alcohol $\mathbf{2 4}$ (Scheme 5). The THP was hydrolyzed, and both alcohols were oxidized to give the keto aldehyde $\mathbf{2 5}$.

With all these aldehydes in hand, we were able to test the chemoselectivity of the aldehyde enamine formation in our conditions, and the results are presented in Table 2. Aldehyde enamines could be rapidly and cleanly prepared in the presence of a wide range of other functional groups, such as a silyl ether (entry 1), a labile dimethylacetal (entry 2), an alkene (entry 3), an ester (entry 4), and even a carboxylic acid (entry 5) and a

(13) Hazeldine, S. T.; Polin, L.; Kushner, J.; White, K.; Corbett, T. H.; Horwitz, J. P. Bioorg. Med. Chem. 2005, 13, 3910.

(14) (a) Sodeoka, M.; Yamada, H.; Shibasaki, M. J. Am. Chem. Soc. 1990, 112, 4906. (b) Fall, Y.; Vidal, B.; Alonso, D.; Gómez, G. Tetrahedron Lett. 2003, 44, 4467.

(15) Frigerio, M.; Santagostino, M. Tetrahedron Lett. 1994, 35, 8019.

7482 J. Org. Chem., Vol. 71, No. 19, 2006 
SCHEME 1. Synthesis of Silyl Ether Aldehyde 16, Acetal Aldehyde 17, and Alkene Aldehyde $18^{a}$
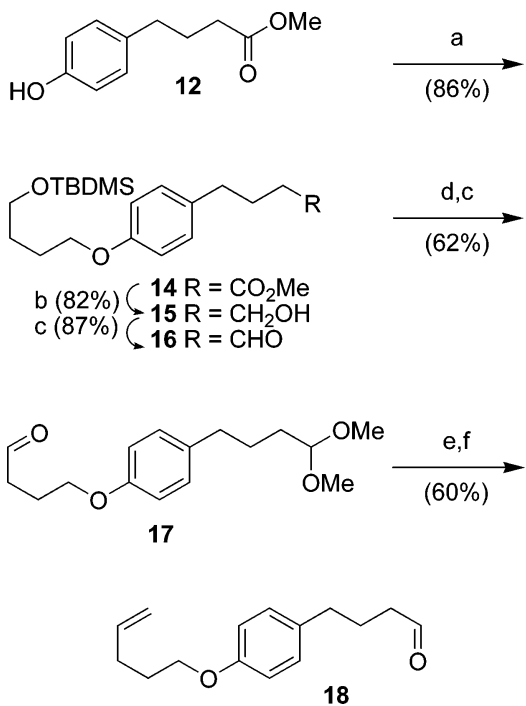

${ }^{a}$ Conditions: (a) I( $\left.\mathrm{CH}_{2}\right)_{4} \mathrm{OTBDMS}$ (13), $\mathrm{K}_{2} \mathrm{CO}_{3}, \mathrm{DMF}$; (b) $\mathrm{LiAlH}_{4}$, $\mathrm{Et}_{2} \mathrm{O}$; (c) $(\mathrm{ClCO})_{2}, \mathrm{DMSO}$; $\mathrm{Et}_{3} \mathrm{~N}$; (d) $\mathrm{HCl}, \mathrm{MeOH}$; (e) $n$-BuLi, $\mathrm{Ph}_{3} \mathrm{PMeBr}$, THF; (f) $\mathrm{HCl}, \mathrm{H}_{2} \mathrm{O}$, THF.

\section{SCHEME 2. Synthesis of Acid Aldehyde 20}

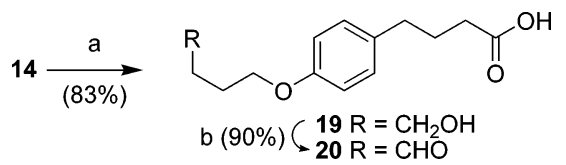

${ }^{a}$ Conditions: (a) $\mathrm{HCl}, \mathrm{H}_{2} \mathrm{O}$; $\mathrm{NaOH}, \mathrm{H}_{2} \mathrm{O}$; (b) IBX, DMSO.

SCHEME 3. Synthesis of Ester Aldehyde $23^{a}$

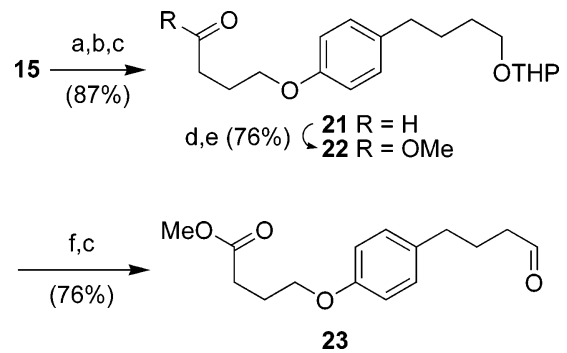

${ }^{a}$ Conditions: (a) DHP, PPTS, $\mathrm{CH}_{2} \mathrm{Cl}_{2}$; (b) TBAF, THF; (c) $(\mathrm{ClCO})_{2}$, DMSO, $\mathrm{Et}_{3} \mathrm{~N}$; (d) $\mathrm{NaClO}_{2}, \mathrm{Me}_{2} \mathrm{C}=\mathrm{CHMe}, \mathrm{H}_{2} \mathrm{O}, t \mathrm{BuOH}$; (e) $\mathrm{CH}_{2} \mathrm{~N}_{2}, \mathrm{Et}_{2} \mathrm{O}$; (f) $\mathrm{HCl}, \mathrm{MeOH}$.

\section{SCHEME 4. Synthesis of Keto Aldehyde $25^{a}$}

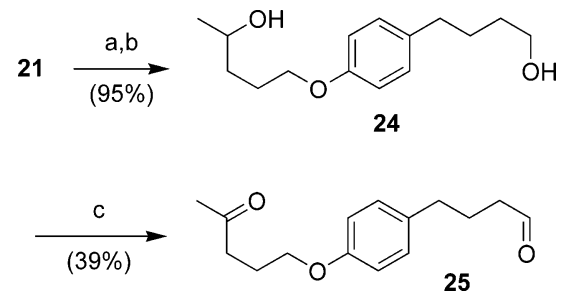

${ }^{a}$ Conditions: (a) $\mathrm{MeMgCl}$, THF; (b) $\mathrm{HCl}, \mathrm{MeOH}$; (c) Dess-Martin periodinane, $\mathrm{CH}_{2} \mathrm{Cl}_{2}$.

ketone (entry 6)! The carboxylic acid of substrate $\mathbf{2 0}$ needed 3.0 equiv of dibenzylamine for a complete conversion since at least 1 equiv was consumed by deprotonation of the carboxylic acid group. The latter could also be deprotonated with sodium hydride prior to the addition of amine; only 1.2 equiv of dibenzylamine was then necessary.
SCHEME 5. Comparison between Aldehyde and Ketone in the Enamine Formation Conditions

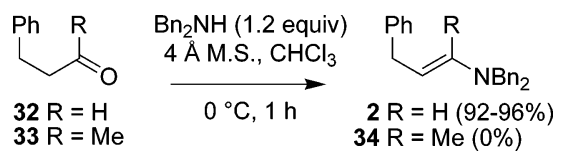

The formation of aldehyde enamine in the presence of a ketone on substrate $\mathbf{2 5}$ (entry 6) is the most striking example of the high chemoselectivity of this method. At $0{ }^{\circ} \mathrm{C}$, only the aldehyde reacted, leaving the ketone moiety intact. This selectivity was verified on simple substrates, as well, containing either an aldehyde (see 32, Scheme 5) or a ketone (33). With only one carbonyl group in each molecule, there is no ambiguity about the selectivity of the enamine formation: after $1 \mathrm{~h}$ at 0 ${ }^{\circ} \mathrm{C}$, the hydrocinnamaldehyde (32) was completely converted to the corresponding aldehyde enamine 2 , whereas 4-phenylbutan-2-one (33) did not react at all in the same conditions. ${ }^{16}$

The results reported in this note for the formation of aldehyde enamines are conversion percentages, calculated by comparing the integration of characteristic enamine versus aldehyde signals on ${ }^{1} \mathrm{H}$ NMR spectra of reaction aliquots. We could not report isolated yields for all enamines because some were not stable and, generally, they could not even be concentrated without extensive loss of material integrity. However, we have shown that these crude enamine solutions could be used in situ successfully for subsequent steps, even in the presence of highly reactive reagent, such as triflic anhydride. ${ }^{2}$ Because a close to equimolar amount of secondary amine is necessary, the only other species in the reaction mixture are the molecular sieves. The sieves could simply be filtered off or left in solution for the next step without hampering the latter.

Besides the observation of aldehyde enamines reported in Table 2 by ${ }^{1} \mathrm{H}$ NMR spectroscopy on reaction aliquots, we wanted to add another element of proof to their formation since most of them could not be isolated. To this purpose, we successfully trapped selected enamines by a sequence of hydroboration-protolysis (Scheme 6). The amine 35 was isolated in $81 \%$ yield after reduction of the enamine intermediate 1 derived from the aldehyde 32 . We also reduced both the carboxylic acid and the enamine groups of compound $\mathbf{3 0}$ to furnish the amino alcohol that was O-silylated in an overall yield of $54 \%$ in TBDMS ether 36 from the acid aldehyde $20 .{ }^{17}$ In a control experiment, a very low yield of amine $\mathbf{3 5}$ was obtained when the starting aldehyde was stirred in the presence of both dibenzylamine and $\mathrm{BH}_{3} \cdot \mathrm{DMS}$. The initial formation of the enamine prior to the reduction is thus crucial in order to get high overall conversion to the amine, which constitutes an additional indication to the formation of the aldehyde enamine intermediate.

In conclusion, we developed very mild reaction conditions for the preparation of enamines derived from aldehydes. High conversions were obtained for a variety of aldehydes, leading to di- and trisubstituted aldehyde enamines, which could be aliphatic or conjugated with aromatic rings. Although most of

(16) Westheimer and Taguchi reported that the same conditions could be employed for the preparation of enamines derived from ketones, but in our hands, the reaction was very sluggish (Westheimer, F. H.; Taguchi, K. J. Org. Chem. 1971, 36, 1570). Moreover, these conditions have never been applied to the preparation of aldehyde enamines.

(17) The hydroxyl group was silylated for characterization purposes since no high-resolution mass spectrum was obtainable from the alcohol intermediate. 
TABLE 2. Chemoselective Aldehyde Enamine Formation

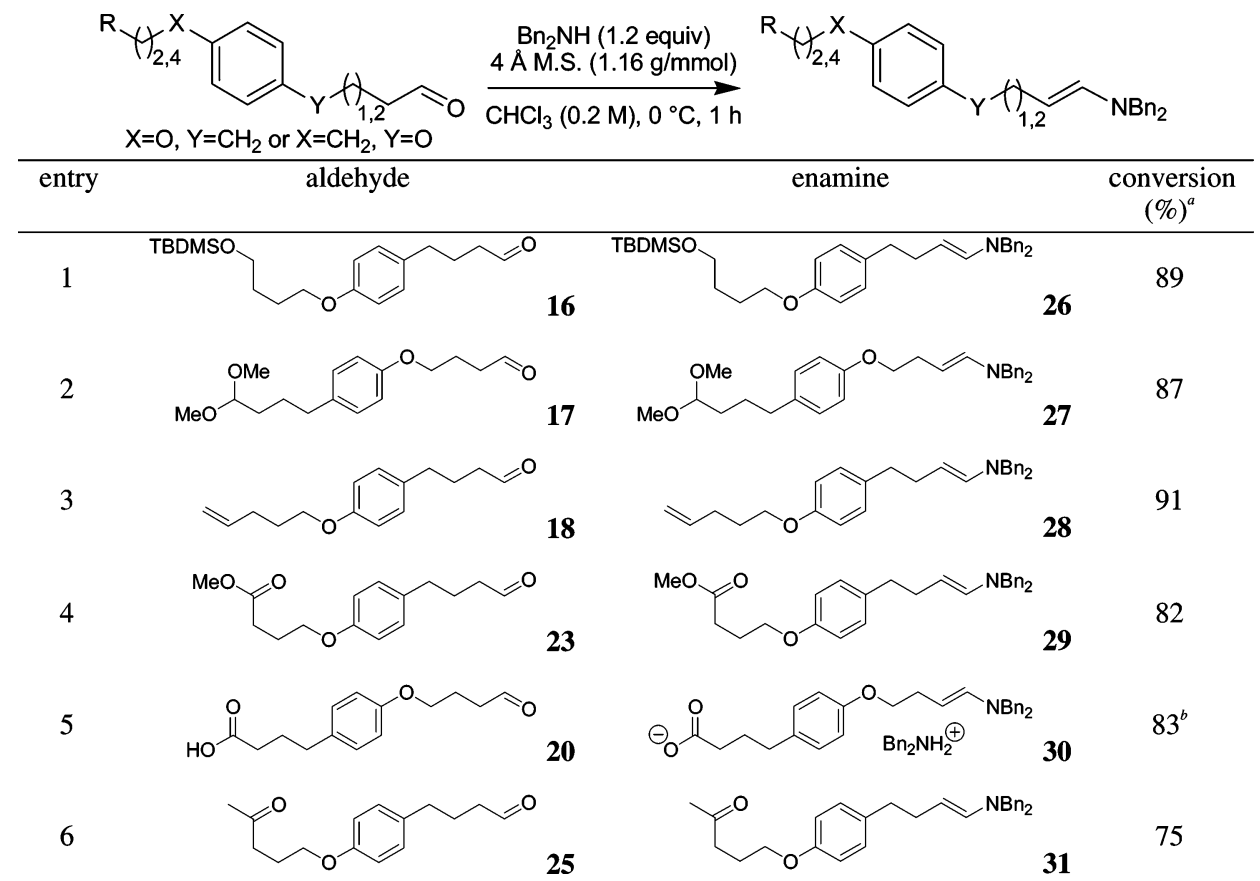

${ }^{a}$ Conversions determined by comparison of the integration of characteristic enamine versus aldehyde signals on ${ }^{1} \mathrm{H}$ NMR spectra of reaction aliquots. ${ }^{b} \mathrm{Bn}_{2} \mathrm{NH}$ (3.0 equiv) was necessary for this conversion. The carboxylic acid $\mathbf{2 0}$ could also be treated with 1.0 equiv of $\mathrm{NaH}$ prior to the addition of only 1.2 equiv of $\mathrm{Bn}_{2} \mathrm{NH}$.

SCHEME 6. Reduction of Selected Enamines ${ }^{a}$

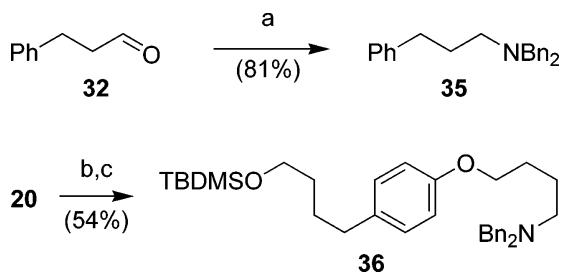

${ }^{a}$ Conditions: (a) i. $\mathrm{Bn}_{2} \mathrm{NH}$ (1.2 equiv), $4 \AA$ M.S., $\mathrm{CHCl}_{3}$; ii. $\mathrm{BH}_{3} \cdot \mathrm{DMS}$; iii. $12 \mathrm{~N} \mathrm{HCl}$; (b) i. $\mathrm{NaH}$ (1.0 equiv), $\mathrm{CHCl}_{3}$; ii. $\mathrm{Bn}_{2} \mathrm{NH}$ (1.2 equiv), $4 \AA$ M.S.; iii. $\mathrm{BH}_{3} \cdot \mathrm{DMS}$; iv. $12 \mathrm{~N} \mathrm{HCl}$; (c) TBDMSCl, imidazole, $\mathrm{CH}_{2} \mathrm{Cl}_{2}$.

the prepared aldehyde enamines must be used in situ as they cannot be isolated due to their sensitive nature, the simplicity of their subsequent use has already been demonstrated. ${ }^{2}$ A wide span of secondary amines proved to react rapidly and cleanly, usually within $1 \mathrm{~h}$ at $0{ }^{\circ} \mathrm{C}$ using an almost equimolar amount of amine. These conditions gave rise to remarkably high chemoselectivity, even completely discriminating between an aldehyde and a ketone. Usual functional groups are also tolerated, even the silyl ether and the dimethylacetal. These groups would not be compatible with the Lewis acids employed in most of the previously known methods for enamine preparation, which adds an important advantage to our method.

\section{Experimental Section}

General Procedure for Aldehyde Enamine Preparation. Molecular sieves (4 $\AA, 750 \mathrm{mg}$ ) were added to a solution of aldehyde $(0.65 \mathrm{mmol})^{18}$ in $\mathrm{CHCl}_{3}(3.0 \mathrm{~mL})$ at $20{ }^{\circ} \mathrm{C}$. The solution was cooled to $0{ }^{\circ} \mathrm{C}$, then the secondary amine $(0.78 \mathrm{mmol})$ was added and the reaction mixture was stirred for $1 \mathrm{~h}$ at $0{ }^{\circ} \mathrm{C}$. Conversion of the aldehyde to the enamine was followed by ${ }^{1} \mathrm{H}$ NMR spectra of $0.1 \mathrm{~mL}$ aliquots sampled from the reaction mixture, filtered, and diluted with $\mathrm{CDCl}_{3}$ in an NMR tube. For aldehyde enamines that were isolated, the reaction mixture was then filtered and concentrated under reduced pressure. The crude material was purified by flash chromatography (silica gel saturated with $\mathrm{Et}_{3} \mathrm{~N},{ }^{19}$ hexanes $-\mathrm{CH}_{2} \mathrm{Cl}_{2}$ ) to afford the corresponding aldehyde enamine.

General Procedure for Aldehyde Enamine Reduction. $\mathrm{BH}_{3}$. DMS (1 equiv) was added to the above solution of crude aldehyde enamine still containing $4 \AA$ molecular sieves. The reaction mixture was stirred at room temperature for $1 \mathrm{~h}$, then $12 \mathrm{~N} \mathrm{HCl}$ was added slowly until a $\mathrm{pH}=2$ was reached. The reaction mixture was stirred for an additional $3 \mathrm{~h}$ at room temperature. $\mathrm{CHCl}_{3}$ was removed under reduced pressure and aqueous $3 \mathrm{~N} \mathrm{NaOH}$ solution was added until a $\mathrm{pH}=12$ was reached. The mixture was filtered, and the aqueous phase was extracted with EtOAc. The organic layers were combined, washed with brine, dried over anhydrous $\mathrm{Na}_{2} \mathrm{SO}_{4}$, filtered, and concentrated under reduced pressure. The crude material was purified by flash chromatography (silica gel) to afford the corresponding amine.

Acknowledgment. This research was supported by the Natural Science and Engineering Research Council (NSERC) of Canada, FQRNT (Québec), the Canadian Fund for Innovation (CFI), and the Universite de Sherbrooke. NSERC undergraduate fellowship to V.D. is also gratefully acknowledged.

Supporting Information Available: Experimental procedures for compounds $1-\mathbf{1 1}, \mathbf{1 4}-\mathbf{3 1}, \mathbf{3 5}$, and $\mathbf{3 6},{ }^{1} \mathrm{H}$ and ${ }^{13} \mathrm{C}$ NMR spectra for compounds $5,7-10,14-25,35$, and 36 , and ${ }^{1} \mathrm{H}$ spectra only for crude aldehyde enamines $\mathbf{1 - 4 , 6}, \mathbf{1 1}$, and 26-31. This material is available free of charge via the Internet at http://pubs.acs.org.

\section{JO0611061}

(18) The reaction was also run on a larger scale with hydrocinnamaldehyde $(32,15.4 \mathrm{mmol}, 2.06 \mathrm{~g})$, and the conversion and reaction time were the same as those recorded when the reaction was run on small scale.

(19) $\mathrm{Et}_{3} \mathrm{~N}$ was added with a pipet to the slurry of silica gel in the eluent until persistent $\mathrm{Et}_{3} \mathrm{~N}$ odor. The slurry was then loaded on the column, and standard elution was used (no $\mathrm{Et}_{3} \mathrm{~N}$ added to the eluent). Using this procedure, practically no $\mathrm{Et}_{3} \mathrm{~N}$ is present in the collected fractions. 